\title{
Transfeminismo e socialismo libertário: uma nota sobre suicídio, necrossexismo e imaginário social conservador
}

\section{Transfeminism and libertarian socialism: a note on suicide, necrosexism and conservative social imaginary}

\section{Inaê Diana Ashokasundari Shravya da Costa Rossi* nascimentodatragedia@gmail.com Universidade Federal do Rio de Janeiro [UFRJ]}

O presente artigo visa abordar as relações existentes entre sexismo e necropolítica a partir dos seus efeitos nos corpos transgêneros, constituindo o que se compreende como corpo transexual. Não se trata de criar ou reforçar um dualismo entre corpo transgênero e corpo transexual, mas identificar no processo de constituição da transexualidade um efeito necrossexista que tem como propósito a destituição do corpo trans enquanto corpo dissidente do imaginário cisgênero.

\section{PALAVRAS-ChaVe Transfeminismo; Socialismo Libertário; \\ Sexismo; Transfobia; Feminismo}

This article aims to address the existing relationships between sexism and necropolitics based on their effects on transgender bodies, constituting what is understood as a transsexual body. It is not a matter of creating or reinforcing a dualism between transgender body and transsexual body, but identifying in the process of constituting transsexuality a necrosexist effect that aims to remove the trans body as a dissident body from the cisgender imaginary through sexual conciliation

\section{KEYWORDS Transfeminism; Libertarian Socialism; \\ Sexism; Transphobia; Feminismo}


Dizer que uma doença como a depressão é socialmente construída, não significa dizer que basta crer que ela não existe, ou que não se deva tomar medicamentos para amenizar seus efeitos. É falacioso partir da premissa de que se é socialmente construído, logo se pode abrir mão da medicamentação. Que diabos significa dizer que ela é socialmente construída? Significa dizer que o seu surgimento ocorre dentro de uma dinâmica específica de um regime de organização social específico. A vida social, nas suas mais variadas dimensões, sejam elas política, econômica e cultural, é o resultado de múltiplos embates de forças entre si. Dizer que uma doença é socialmente construída implica dizer que há mecanismos nesse formato de sociedade que vão preparar o sujeito para uma determinada doença. Isso tem implicações materiais, a inscrição da doença é somática. Bakunin, em um texto chamado Programa e Objetivo da Organização Secreta Revolucionária dos Irmãos Internacionais, nos diz que:

[...] todo indivíduo humano é o produto involuntário de um meio natural e social no seio do qual nasceu, desenvolveu-se e do qual continua a sofrer influência. As três causas de toda a imoralidade humana são: a desigualdade tanto política quanto econômica e social; a ignorância que é seu resultado natural e sua consequência necessária: a escravidão. https://www.marxists.org/portugues/bakunin/ano/mes/secreta.htm

A depressão é interessante ao neoliberalismo pois auxilia o processo de individuação. Que haveria de mais seu, sua propriedade privada mais íntima, senão uma doença que te acomete no seu âmago, lá onde mais ninguém além de você pode estar? É preciso centralizar a ideia da sociedade como criadora, pensar a ontologia do sujeito depressivo a partir duma perspectiva materialista sociológica, ou seja, pensar de que forma a disposição espacial da sociedade possibilita o surgimento de doenças como a depressão e a ansiedade.

Quando consideramos grupos designados minoritários, se percebe uma predominância dessas doenças. O número de pessoas trans com depressão e ansiedade - e consequentemente, ideação suicida - tem aumentado a cada dia que passa. Segundo uma matéria publicada no dia 29 de junho de 2018 no site da ANTRA -Brasil' :

Existe um mito relacionado às questões de saúde mental das pessoas Trans,

1 https://antrabrasil.org/2018/06/29/precisamos-falar-sobre-o-suicidio-das-pessoas-trans/ 
onde está posto que a Travestilidade ou Transexualidade em si, são fatores que causariam ideações suicidas, depressão, ansiedade ou outras questões de saúde mental. São ideias sob um viés estigmatizante e patologizante, que ignoram os resultados positivos de uma transição em ambientes acolhedores, com apoio dos pais, amigos e familiares, acesso a tratamentos de saúde e acompanhamento nas questões de transição para quem deseja ou precisa, garantia de atendimento humanizado, respeito e uso de nome social e banheiro de acordo com a identidade de gênero das pessoas trans nos espaços sociais. Estes são alguns dos fatores que podem vir a garantir a qualidade e melhora da saúde mental de nossa população.

Ou seja, há um desvio da multicausalidade para uma causalidade unilateral, depositando sobre o indivíduo a responsabilidade de efeitos que lhe afetam diretamente, quando estes são, em realidade, efeitos de mecanismos de poder e elementos de saber que incidem direta e indiretamente sobre o indivíduo, o constituindo enquanto sujeito. Não existem, se seguirmos a perspectiva libertária adotada pelo filósofo Bakunin, predeterminações, causas unilaterais, características inatas que determinem o homem ou mesmo a sociedade, compreendo que, o que vem a unicamente determinar o ser é a ação. Nada além de relações concretas nos interessa aqui. Assim, se o que determina o ser é a ação - em oposição a uma substância inata, ou seja, desprovida de ação -, podemos falar em termos de capacidade de agir. Se o indivíduo, por sua vez, tem sua capacidade de agir restringida, atrofiada, cerceada, ele mesmo terá a sua autonomia, sua capacidade de decisão minada. Se levarmos em conta como que fatores de classe, raça, gênero, e diversidade funcional se perpassam, e também considerando que no regime de organização social capitalista há um cada vez maior número de desigualdades - e que só aumentará cada vez mais, pois a sua arquitetura é essa -, podemos dizer sem receios que a capacidade de agir de pessoas trans, assim como de pessoas negras, de pessoas com diversidade funcional, de pessoas pobres, de pessoas camponesas, de pessoas indígenas, de mulheres (cis e trans), e por aí vai, é desumanizada, ou seja, o que se presumiria ser a capacidade de agir ${ }^{2}$ de um ser

2 Por capacidade de agir me refiro à garantia dos direitos básicos. Ou seja, me refiro à capacidade de escolha, de poder analisar e discernir sobre o que lhe é apresentado para constituir a si mesm@. Prostituição e cabeleireira são profissões às quais mulheres trans/travestis são empurradas socialmente. Sua capacidade de agir inexiste aí, dado que a adesão a essas formas de trabalho não se dá por uma apresentação prévia das mesmas, seguida de uma escolha passível de revogação. Ou se adere a essas formas de trabalho, ou se passa a realizar pequenos furtos. Em ambos os casos há uma multicausação social, como os já mencionados gênero, raça, classe, diversidade funcional e por aí vai. Há exceções, de certo, e é exatamente por isso que falo em termos de multicausação social. Isso também não significa dizer que uma pessoa optasse pela prostituição ou cabeleireira, mas aí teríamos que reconsiderar essas mesmas profissões fora do contexto capitalista, por exemplo. Se elas existiriam ou não numa sociedade comunista eu realmente não sei dizer, e também não me interessa especular a esse respeito. Me interessa, sim, focar no que há de concreto neste momento a respeito de nossos modos de viver, sobre como 
humano tal como apresentado na Declaração Universal dos Direitos Humanos, não se aplicaria aos grupos sociais citados. Quaisquer formas de violência, direcionadas a qualquer um desses grupos, deveriam ser tratadas como crimes contra a humanidade. Afinal de contas, não seriam essas pessoas humanas?

Uma das multicausações é a biológica, e não se trata aqui de um determinismo biológico, mas de um preparo mesmo do corpo ${ }^{3}$ para incorporar aquela doença. A esse tipo de incorporação eu gostaria de designar necrossexismo. Necrossexismo porque se trata da articulação entre sexismo e necropolítica. De que forma esse necrossexismo agiria sobre os corpos trans? Pela instituição da disforia de gênero como característica indissociável da transgeneridade ${ }^{4}$. $\mathrm{O}$ fato mesmo de a disforia de gênero ser abordada pelo discurso médico como algo exclusivo da transgeneridade, ignorando que há também casos de disforia de gênero entre pessoas cisgêneras - ou talvez fosse o caso de pensar a transgeneridade em termos de possibilidade de existência -, já nos diz algo. Ela nos diz que para o discurso médico a transgeneridade só existe enquanto corpo portador de uma doença, de um mal-estar. Mal-estar esse provavelmente decorrente da corrupção do corpo que se presume o corpo ideal, que é o corpo cisgênero, se considerarmos os burburinhos que surgem aqui e ali. Burburinhos esses que não de isolam da sociedade no qual circulam, importa lembrar. Um corpo tido socialmente como um corpo doente, portador de uma doença. Farei uso do conceito de "imaginário social" para endossar o conceito de necrossexismo. Utiliza-se o conceito de "bloco imaginário" ou "imaginário social", nos diz Eduardo Colombo:

[...] quando se faz alusão ao funcionamento da sociedade sobre a base de uma série de ideias e valores que se organizam como uma espécie de 'campo de força' que atrai e orienta os diversos conteúdos de todo um universo de representações (expressado em instituições,

podemos nos livrar das correntes-gênero, correntes-raça, correntes-sexualidade, correntes-nacionalidade, correntes-endossexualidade, e por aí vai.

3 Falo brevemente disso num texto anterior: https://transfeminismo.com/breve-comentario-sobre-nossos-corpos/

4 Compreender a disforia de gênero como sendo socialmente elaborada não significa dizer que ela não incida diretamente sobre os corpos. Somos criaturas sociais, portanto, tudo que diz respeito ao âmbito social incide diretamente sobre nós, nos destrói e nos cria. Há, neste caso, uma dialética indivíduo-sociedade, ou seja, nem é algo genético - em termos neurológicos -, nem algo absolutamente externo - que mais se assemelharia a uma injunção divina sobre o indivíduo, o que não é o caso-. Portanto, muito cuidado ao realizar essa leitura. Faço essa ressalva tendo em mente que essa parte pode ser desonestamente utilizada por ativistas duma determinada corrente idealista feminista conhecida como feminismo radical para atacar mulheres trans/travestis. 
ideologias, mitos ou formas sociais). Quando se consolida esse universo, supõe uma evidente limitação para o pensamento e a ação .

Assim, um imaginário social conservador que tem em vista cisgenerizar os corpos - processo esse que, seguindo Foucault, poderíamos designar estatização do biológico ${ }^{6}$ - depende da abjeção da transgeneridade, da abjeção da indefinição dos corpos. Consolidado o imaginário social conservador cisgênero, a população trans se depara como única realidade possível uma vida agachada, uma vida de joelhos, uma vida submissa, uma vida prostrada, adaptando a fala de Fanon a respeito do colonizado?.

Toda pessoa trans é invejosa, pois deseja ter a vida da pessoa cisgênera. Ter a sua educação, a sua saúde, a sua moradia, a sua afetividade, o seu trabalho, o seu lazer. A normatividade cisgênera não lhe parece nem um pouco torturante, senão esplendorosa. Trata-se, literalmente, de querer integrar a realidade de um presídio, o presídio de um corpo, pois ali há a certeza de que se alimentará ainda que em porções que não lhe são suficientes, de que terá onde dormir. Não à toa a hormonização farmacêutica pode se tornar um vício, e um vício fatal, expondo a vida a riscos para além daqueles que aos quais o necrossexismo subordina a população trans. Afinal de contas, não sabe nunca se esta passou ou não dos limites. Presume sempre que possui culpa: culpa por lhe agredirem, culpa por lhe odiarem, culpa por não lhe respeitarem, culpa por existir como sujeito abjeto. E isso é efeito do necrossexismo exercido cuidadosamente em cada prática transfóbica que se mascara no argumento de que "não foi intencional", fazendo retornar a pessoa trans ao seu lugar prescrito de sentir-se culpada. Lembro de quando a minha noiva disse para a mãe dela que ela estava se envolvendo afetivamente com uma mulher trans (eu, no caso), ao que a mãe dela indagou: "mas ela não tem doença?".

5 Original em espanhol acompanhado da tradução ao português feita por mim: https:/lapeste. org/2018/10/el-imaginario-revolucionario-una-aproximacion-a-las-propuestas-de-eduardo-colombo/ . Em outros textos eu designei esse imaginário social conservador como sendo a tão famosa "ideologia de gênero".

6 Ao realizar uma aproximação entre a cisgeneridade e a estatização do biológico/ racismo de Estado, não tenho em mente atribuir uma substancialidade racista a pessoas cisgêneras, mas denunciar, senão atentar, o que há de racista na constituição da cisgeneridade - seja elementos de saber sobre ela, seja nos mecanismos de poder que garantam seu surgimento -, que será tida como causa imanente de toda uma educação voltada para a cisgenerização dos corpos. O surgimento do Estado-Nação se encontra atrelado com a afirmação do corpo cisgênero, como muito bem expõe Paul Preciado em sua obra Terror Anal, de tradução minha, lançada pela Imprensa Marginal no início do ano passado.

7 Me refiro ao livro Os Condenados da Terra. 
O preparo do corpo para a incorporação da doença não ocorre interessadamente ou via servidão voluntária, mas por um processo de adoecimento. Muitas das vezes em decorrência do constrangimento pelos quais as pessoas trans passam diariamente, elas evitam frequentar determinados espaços, circular durante determinados horários. No início da minha transição, assim que eu fui expulsa de casa, passei a andar mais à noite para não ter que lidar com os estresses com os quais me deparava durante o dia. Logo fiz amizade com outras pessoas trans que também moravam naquele bairro. Antes de eu ser expulsa, quando eu sequer imaginava o que seria a transgeneridade - mas sabia que não era homem -, eu não via essas pessoas, elas não faziam parte do meu convívio. Isso se dava exatamente porque o horário que eu andava fora de casa não contemplava essas pessoas, às quais eu me somei logo depois à expulsão. Essas pessoas sempre estiveram ali, mas foi necessária uma mudança radical na minha vida para que eu me desse conta. Hoje em dia me questiono quantos outros modos de viver não ocorrem sem que eu me dê conta. Que outras presenças não notamos? Por que não notamos?

Dado que o regime de organização social no qual sobrevivemos visa a uma estatização dos modos de viver, do biológico, enaltecendo o que se compreende por cisgeneridade, o que podemos esperar das instituições senão a tentativa de nos expor à morte? É nisso que consiste o necrossexismo, a exposição de nossos corpos à morte, ao extermínio. Quando um professor se recusa a chamar @ alun@por seu nome social ${ }^{8}$ ou pelo pronome adequado, ou não leva em consideração o contexto d@alun@ quanto à sua participação dentro do ambiente estudantil, por exemplo, este professor está sim sendo cúmplice de uma política de morte que assola a população trans. E não se trata nem um pouco absurdo afirmar isso, se considerarmos que o país lidera o ranking de assassinatos de pessoas trans ${ }^{9}$ no mundo, sendo que dessas pessoas assassinadas, em torno de $82 \%$ são negras ${ }^{10}$. São assassinatos que ocorrem de maneira brutal, com requinte de crueldade ${ }^{11}$. Assassinatos por si só já são um absurdo. A situação se torna mais cabulosa se observarmos como se dão nos assassinatos de pessoas trans, com casos onde a vítima teve seu coração arrancado e uma imagem de uma

8 Deixo aqui a seguinte pergunta: que nome não é social? Essa designação esconde um enunciado que qualifica o nome duma pessoa trans como sendo um nome falso.

9 https://oglobo.globo.com/sociedade/brasil-segue-no-primeiro-lugar-do-ranking-de-assassinatos-de-transexuais-23234780 ou https://www.plural.jor.br/noticias/vizinhanca/violencia-contra-pessoas-trans-ainda-e-invisivel/

$10 \mathrm{https}$ //www.almapreta.com/editorias/realidade/segundo-dossie-82-das-pessoas-trans-assassinadas-no-brasil-sao-negras

11 https:/www.uol.com.br/universa/noticias/redacao/2019/01/29/163-pessoas-trans-foram-mortas-em-2018-no-brasil-83-dos-crimes-sao-crueis.htm 
santa foi posta no seu lugar, pois para o assassino a vítima era um demônio ${ }^{12}$. A absolvição do assassino ${ }^{13}$ diz sobre como os assassinatos de pessoas trans são tratados socialmente: como parte constituinte da normalidade cisgênera. Quelly, a travesti brutalmente assassinada, foi encontrada com o tórax aberto. Antes reverberava, hoje nem tanto, em círculos feministas a palavra de ordem "tire seu rosário do meu ovário", referente ao direito de abortar. Não seria a hora de também enunciarmos a palavra de ordem "tire sua santa do nosso tórax" referente ao nosso direito de viver?

Levando em conta tudo o que foi dito anteriormente, podemos compreender como se dá essa construção social da depressão. O regime de organização social não é algo abstrato, impalpável, mas concreto, que incide materialmente sobre os corpos, os quais são eles mesmos, também, efeitos de sua ação. Tomarmos medicamentos antidepressivos não é a solução, mas nos auxilia. Reformas sociais que garantam algum tipo de garantia de renda mensal também auxiliam. Uma cirurgia de redesignação genital auxilia, assim como a facilidade em retificar documentos, cirurgias de mastectomia, histerectomia, e por aí vai. Tudo isso auxilia. Há que se reconhecer que reformas sociais auxiliam, mas elas não são a solução. Enquanto tivermos nossa capacidade de agir cerceada, não poderemos realizar escolhas e, consequentemente, viver uma vida plena. Claro, por capacidade de realizar escolhas não falo de uma escolha individualista acima de qualquer coisa. Me refiro a uma capacidade de escolha dentro de condições específicas. Uma guitarrista que realiza improvisações na guitarra, as realiza com base no que ela conhece de antemão, e não um tanto-fez-tanto-faz. Cabe pensar um regime de organização social que nos ofereça uma capacidade de escolha ampla, e que este mesmo leque de escolhas esteja suscetível a alterações, inclusões, e - se necessário - exclusões. Temos que reconhecer que o regime de organização social capitalista nada nos tem a oferecer. Muito pelo contrário, há apenas extração e exploração. Nossas subjetividades são produzidas politicamente pensadas para atender uma dinâmica econômica, e aí se encontram doenças como a depressão, a ansiedade, que nos açoitam a todo instante. Lembrar que a expectativa de vida de uma pessoa trans no Brasil é de 35 anos me suga, me exaure, me deixa ansiosa. Quando acho que não tenho feito nada de importante - e aqui cabe questionar de que importância se trata -, vem a depressão e me arrasta. A sensação de que não posso compartilhar isso com

12 https://observatoriog.bol.uol.com.br/noticias/2019/10/homem-que-arrancou-o-coracao-de-travesti-e-absolvido

13 Trata-se de uma observação em contraste com outros casos de assassinato. De modo algum almejo realizar uma defesa do punitivismo, muito pelo contrário. A observação aqui reside sobre como o caso foi tratado. Será que se invertêssemos as posições o caso teria o mesmo encaminhamento? 
amig@s cisgêneros, por exemplo, é efeito de uma política de inimizade que tem cada vez agido micrologicamente, instaurando desconfiança, garantindo assim a conservação desse regime de organização social.

Dizem Leila Míccolis e Herbert Daniel no livro Jacarés \& lobisomens que:

[...] coragem é preciso ter para escapar da facilidade da justificação e do apelo humilhante à uma vaga 'compreensão' ou piedade. Ninguém precisa pedir desculpa pela própria sexualidade; precisa fundamentalmente livrar-se de uma culpabilidade imobilizadora. Coragem mesmo é preciso para amar a vida com todo o seu cortejo de disparidades. (1983)

Infelizmente há atualidade nessa citação, que data de 1983. Isso talvez tenha ocorrido porque nos detivemos em reivindicar reformas sociais. Reivindicar reformas sociais não é um problema. O problema é quando se tem em vista somente elas em si mesmas, e não como maneiras de se criar condições para que se realize uma revolução social, a qual mudaria radicalmente o regime de organização social:

Convencidos de que o mal individual e social reside muito menos nos indivíduos do que na organização das coisas e nas posições sociais, nós seremos humanos tanto por sentimento de justiça quanto por cálculo de utilidade, e destruiremos sem piedade as posições e as coisas a fim de poder, sem nenhum perigo para a revolução, poupar os homens. Negamos o livre-arbítrio e o pretenso direito da sociedade de punir. A própria justiça tomada no seu sentido mais humano e mais amplo, é apenas uma ideia, por assim dizer, negativa e de transição; ela coloca o problema social mas não o resolve, indicando apenas o único caminho possível para a emancipação, isto é, de humanização da sociedade pela liberdade na igualdade; a posição positiva só poderá ser dada pela organização cada vez mais racional da sociedade. Esta solução tão desejada, ideal de todos nós, é a liberdade, a moralidade, a inteligência e o bem-estar de cada um pela solidariedade de todos, a fraternidade humana. (. . .) Para fazer uma revolução radical é preciso, pois, atacar as posições e as coisas, destruir a pro- 
Transfeminismo e socialismo libertário: uma nota sobre suicídio, necrossexismo e imaginário social conservador
Inaê Diana Ashokasundari

Shravya da Costa Rossi [UFR]]

priedade e o Estado, assim não se terá a necessidade de destruir os homens, e de condenar-se à reação infalível e inevitável que o massacre dos homens nunca deixou e não deixará nunca de produzir em cada sociedade. ${ }^{14}$

Nossas vidas importam. Nossas vidas não são elementos isolados do regime de organização social. Nossas vidas importam. Não falo da minha, da sua, mas das nossas vidas. Falar de nossas vidas implica falar do regime de organização social no qual estamos inserid@s. Se esse regime de organização social o tempo inteiro nos vulnerabiliza mais e mais, nos expondo à morte, não há outro caminho senão mudarmos esse regime de organização social. O que queremos destruir nós já sabemos. Mas também nos cabe levantar a seguinte interrogação: Que mundo nós feministas queremos inventar?

$14 \mathrm{https}: / /$ www.marxists.org/portugues/bakunin/ano/mes/secreta.htm

Recebido em: 17.03.2020| Aprovado em: 05.04.2020 $R$ eferência Bibliográfica

BAKUNIN, Mikhail. Programa e Objetivo da Organização Secreta Revolucionária dos Irmãos Internacionais. Disponível em: https://www.marxists.org/portugues/ bakunin/ano/mes/secreta.htm. Acessado em: 27 out. 2019.

COLOMBO, Eduardo. El espacio político de la anarquía. Montevideo: Nordan-Comunidad, 2000.

. El imaginario social. Montevideo: Nordan-

-Comunidad, 2002.

. El lenguaje libertario, varios textos compilados por Christian Ferrer. Buenos Aires: Tupac Ediciones, 2005. . La voluntad del pueblo. Buenos Aires: Tupac Ediciones, 2006.

DANIEL, Herbert; MÍCCOLIS, Leila. Jacarés e Lobisomens - Dois Ensaios sobre a Homossexualidade. Rio de Janeiro: Achiamé Socii, 1983.
FANON, Frantz. Os Condenados da Terra. Rio de Janeiro: Editora Civilização Brasileira, 1968.

PRECIADO, Paul. Terror Anal. Tradução de Inaê Diana Ashokasundari Shravya da Costa Rossi. Rio de Janeiro: Imprensa Marginal, 2019.

ROSSI, Inaê Diana. Breve Comentário Sobre Nossos Corpos. Publicado em: 19 de novembro de 2019. Disponível em: https://transfeminismo.com/breve-comentario-sobre-nossos-corpos/

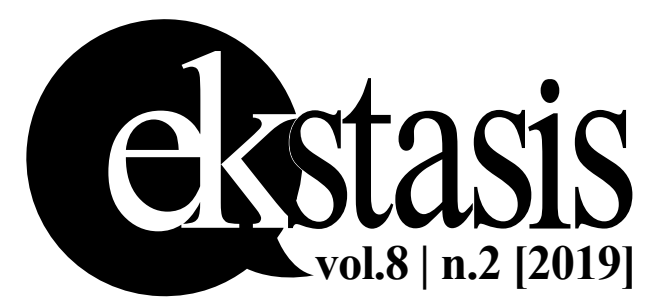

